\title{
Functional characterization of two clip domain serine proteases in innate immune responses of Aedes aegypti
}

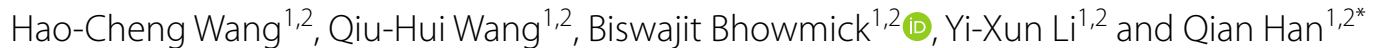

\begin{abstract}
Background: Clip domain serine proteases (CLIPs), a very diverse group of proteolytic enzymes, play a crucial role in the innate immunity of insects. Innate immune responses are the first line of defense in mosquitoes against the invasion of pathogenic microorganisms. The Toll pathway, immunodeficiency (IMD) pathway and melanization are the main processes of innate immunity in Aedes aegypti. CLIPS are classified into five subfamilies-CLIPA, CLIPB, CLIPC, CLIPD, and CLIPE-based on their sequence specificity and phylogenetic relationships. We report the functional characterization of the genes that code for two CLIPs in Ae. aegypti (Ae):Ae-CLIPB15 and Ae-CLIPB22.

Methods: Clustal Omega was used for multiple amino acid sequence alignment of Ae-CLIPB15 and Ae-CLIPB22 with different CLIP genes from other insect species. The spatiotemporal expression profiles of Ae-CLIPB15 and Ae-CLIPB22 were examined. We determined whether Ae-CLIPB15 and Ae-CLIPB22 respond to microbial challenge and tissue injury. RNA interference (RNAi) was used to explore the function of $A e-C L I P B 15$ and Ae-CLIPB22 in the defense of Ae. aegypti against bacterial and fungal infections. The expression levels of nuclear factor kappa B (NF-kB) transcription factors RELI and REL 2 in the Toll pathway and IMD pathway after bacterial infection were investigated. Finally, the change in phenoloxidase (PO) activity in Ae-CLIPB15 and Ae-CLIPB22 knockdown adults was investigated.

Results: We performed spatiotemporal gene expression profiling of Ae-CLIPB15 and Ae-CLIPB22 genes in Ae. aegypti using quantitative real-time polymerase chain reaction. These genes were expressed in different stages and tissues. The messenger RNA (mRNA) levels for both genes were also up-regulated by Gram-negative bacteria Escherichia coli, Gram-positive bacteria Staphylococcus aureus and fungal Beauveria bassiana infections, as well as in the tissue injury experiments. RNAi-mediated knockdown of Ae-CLIPB15 led to a significant decrease of PO activity in the hemolymph of Ae. aegypti, while other RNAi experiments revealed that both Ae-CLIPB15 and Ae-CLIPB22 were involved in immune defense against bacterial and fungal infections. The mRNA expression of NF-KB transcription factors REL1 and REL2 in the Toll pathway and IMD pathway differed between Ae-CLIPB15 and Ae-CLIPB22 knockdown mosquitoes infected with bacteria and wild type mosquitoes infected with bacteria.
\end{abstract}

Conclusions: Our findings suggest that Ae-CLIPB15 and Ae-CLIPB22 play a critical role in mosquito innate immunity, and that they are involved in immune responses to injury and infection. Their regulation of transcription factors and $\mathrm{PO}$ activity indicates that they also play a specific role in the regulation of innate immunity.

\footnotetext{
*Correspondence: qianhan@hainanu.edu.cn

1 Laboratory of Tropical Veterinary Medicine and Vector Biology, School

of Life Sciences, Hainan University, Haikou, Hainan 570228, People's

Republic of China

Full list of author information is available at the end of the article
}

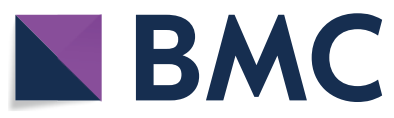

Ther(s) 2021. Open Access This article is licensed under a Creative Commons Attribution 4.0 International License, which permits use, sharing, adaptation, distribution and reproduction in any medium or format, as long as you give appropriate credit to the original author(s) and the source, provide a link to the Creative Commons licence, and indicate if changes were made. The images or other third party material in this article are included in the article's Creative Commons licence, unless indicated otherwise in a credit line to the material. If material is not included in the article's Creative Commons licence and your intended use is not permitted by statutory regulation or exceeds the permitted use, you will need to obtain permission directly from the copyright holder. To view a copy of this licence, visit http://creativecommons.org/licenses/by/4.0/. The Creative Commons Public Domain Dedication waiver (http://creativeco mmons.org/publicdomain/zero/1.0/) applies to the data made available in this article, unless otherwise stated in a credit line to the data. 
Keywords: Innate immunity, Aedes aegypti, Prophenoloxidase, RNA interference, Clip domain serine proteases, Microbial infection

\section{Graphical Abstract}
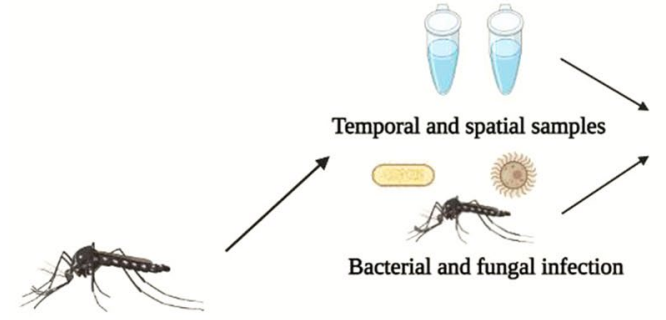

Bacterial and fungal infection

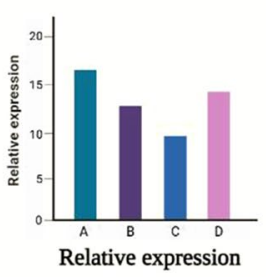

Relative expression
Two clip-domain serine proteases (CLIPB15 and CLIBP22) of Aedes aegypti

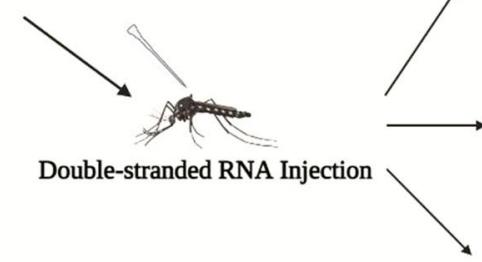

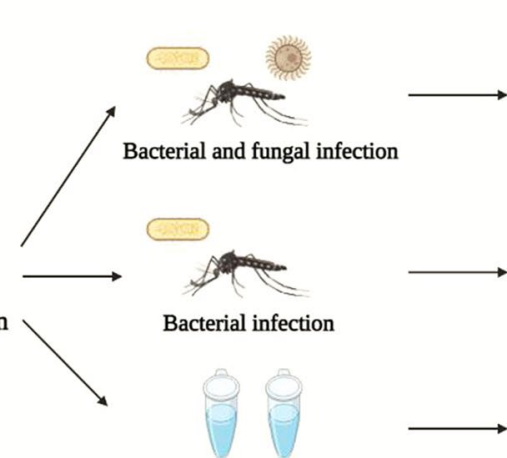

Tissue fluid containing hemolymph

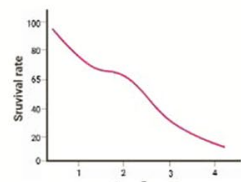

survival rate

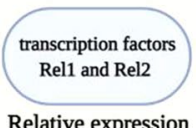

Relative expression

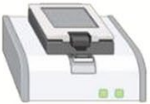

PO activity

\section{Background}

Mosquito-borne diseases are a major public health problem throughout most of the world [1]. For instance, there are more than 100 million annual cases of dengue fever, a viral disease transmitted by Aedes aegypti. Despite the burden of mosquito-borne diseases on human populations, our understanding of the relationships between pathogens and their mosquito hosts remains limited [2]. Studies have shown that innate immunity plays a key role in the interaction between pathogens and their vectors, and that pathogens face multiple barriers in the innate immune system of mosquitoes. Therefore, the study of vector immunity and its interaction with pathogens is important for the development of new vector disease control strategies [3].

Mosquitoes lack acquired immunity, but their innate immune system can destroy various prokaryotic and eukaryotic pathogens [4]. In arthropods, innate immunity plays an important role in limiting pathogen infection through the production of molecules such as antimicrobial peptides (AMPs), through phagocytosis and encapsulation, and by the secretion of physical barriers and melanization [5]. Melanization is an immune response of arthropods to a wide range of viruses [6], bacteria [7, 8], fungi [9], nematodes associated with chromogenic bacteria [10] and other eukaryotic parasites
[11-13]. This immune response is regulated by prophenoloxidase (proPO), which mediates the conversion of tyrosine to melanin; recognition of a pathogen triggers a serine protease cascade in which activated serine proteases cleave proPO to produce phenoloxidase (PO) [14]. The Toll pathway and immunodeficiency (IMD) pathway are two major pathways of the innate immune response in arthropods, and are responsible for the production of AMPs and other effectors [15]. In Ae. aegypti, the activation of genes coding for AMPs and other immune effectors is achieved by releasing nuclear factor kappa $\mathrm{B}$ (NF-kB) transcription factors REL1 and REL2, which are homologous to those in Drosophila melanogaster [16].

Clip domain serine proteases (CLIPs), non-digestible serine proteases found in the hemolymph of insects and other arthropods, are key components of the insect immune response. CLIPs have been identified in arthropods and mollusks, and the genes coding for them comprise a large gene family in the insect genome [17-22]. CLIPs are secreted into hemolymph in the form of a zymogen and need to be hydrolyzed and activated by cleavage [14]. CLIPs have a N-terminal with disulfide bonds and a $\mathrm{C}$-terminal domain with protease activity. Infection can stimulate the activation of CLIP protease in hemolymph, which can specifically cleave at a site in the $\mathrm{N}$ terminal domain of the protease, resulting in the 
creation of a double-stranded enzyme in which the CLIP domain and the protease domain are connected by disulfide bonds. Once CLIP proteases are activated, they are regulated by serine inhibitors in hemolymph plasma [23-26]. The functions of CLIPs include proteolytic activation of the Spätzle cytokine to form active Toll ligands for the synthesis of AMPs and the specific activation of proPO that is needed for melanization. However, some CLIPs have a non-catalytic protease-like domain and $\mathrm{N}$-terminal clip domain, which are called clip domain serine protease homologs (CSPHs). Despite their lack of enzymatic activity, CSPHs seem to play an essential role in the immune response of mosquitoes. In melanization, the cleavage and activation of proPO require CSPHs as cofactors [27-29]. Two CSPHs, serine protease homolog (SPH)1 and SPH2 in Manduca sexta, are cofactors of proPO activating enzymes (PAP)1 and PAP3, which effectively cleave and activate proPO [29-31]. The precursors of SPH1 and SPH2 cannot activate proPO [29, 32 ] and need to be treated with PAP3 and PAP1 to generate activated SPH1 and SPH2 [31,33]. Tenebrio molitor CSPH1 [28] and Holotrichia diomphalia proPO activating factor II [34] have also been proven to be indispensable CSPHs for the activation of proPO. CSPHs are also involved in cell adhesion and bacterial conditioning [35].

In Ae. aegypti, the family of CLIP proteases can be classified into five subfamilies: CLIPA, CLIPB, CLIPC, CLIPD and CLIPE [17]. Of the 82 CLIPs, 62 belong to CLIPB; CLIPC and CLIPD are expected to show serine protease activity. CLIPA and CLIPE comprise 17 CSPHs. In addition, 15 CLIPs and two CSPHs have special domains and are considered to play essential regulatory roles in immune responses.

Through evolutionary analysis we found that there are two members of the CLIPB subfamily in Ae. aegypti (Ae): Ae-CLIPB15 and Ae-CLIPB22. These CLIPs are similar to those of other organisms such as Drosophila melanogaster, Bombyx mori and Manduca sexta [3]. However, compared with the CLIPs of different species of mosquitoes, such as Aedes albopictus and Anopheles gambiae, they are highly conserved, indicating that they may play an important role in the regulation of innate immunity in Ae. aegypti. Thus, we decided to examine their role in immune response and immune pathways, and especially their role in the proPO activation pathway. Here, we report the involvement of Ae-CLIPB15 and Ae-CLIPB22 in the defense of Ae. aegypti against bacterial and fungal infections. The results showed that these two serine proteases enable Ae. aegypti to resist infection by exogenous pathogenic microorganisms. They are also involved in regulating $\mathrm{PO}$ activity and transcription factors of innate immunity such as the Toll and IMD pathways. Our study shows that Ae-CLIPB15 and Ae-CLIPB22 are regulatory factors of the mosquito immune system, and thus contributes to a better understanding of the mechanisms of immune regulation in insects.

\section{Methods \\ Mosquito rearing}

The Ae. aegypti Rockefeller strain was maintained in the insectary at Hainan University. Eggs of Ae. aegypti were placed in a $30 \times 25 \times 8$-mm plastic feeding pot and maintained at $27{ }^{\circ} \mathrm{C}$ and $90 \pm 5 \%$ relative humidity. Upon hatching, the larvae were reared in water with fish food provided ad libitum. The adult mosquitoes were kept in the insectary at $26 \pm 1{ }^{\circ} \mathrm{C}$ and $80 \pm 5 \%$ relative humidity under a 16-h light:18-h dark cycle with access to water and $8 \%$ sugar ad libitum. Three-day-old mosquitoes were used for the experiments.

\section{Multiple amino acid sequence alignment}

We retrieved protein sequences of CLIPs from the National Center for Biotechnology Information database (https://www.ncbi.nlm.nih.gov/) that have been studied in other insect species. Clustal Omega software (https:// www.ebi.ac.uk/Tools/msa/clustalo/) was used for multiple amino acid sequence alignment of Ae-CLIPB15 and $A e-C L I P B 22$ with different CLIPs from other insect species.

\section{Sampling of different stages and tissue samples of mosquitoes}

To examine the temporal expression of Ae-CLIPB15 and $A e-C L I P B 22$, we used different stages of the mosquito, including eggs, first-instar to fourth-instar larvae, white and black female pupae, white and black male pupae, and female and male adults. To examine the spatial expression of $A e-C L I P B 15$ and $A e-C L I P B 22$, different tissues of female adults, including those of the thorax, legs, fat body, midgut, ovary, and Malpighian tubule were collected. Adult female mosquitoes were anesthetized at low temperature and placed in a Petri dish. Each tissue sample comprised material that was collected from about 30 mosquitoes. A total of 50 first- and second-instar larvae and ten larvae at other instar stages were collected from each tube. There were three repeats for each life cycle stage and type of tissue sample.

\section{Bacterial and fungal infection and tissue injury experiments}

For bacterial infection, Escherichia coli (DH5 $\alpha$ ) [36] and Staphylococcus aureus (ATCC43300) were obtained from Hainan University. Both were cultured in $37{ }^{\circ} \mathrm{C}$ Luria-Bertani liquid medium, and their growth monitored by the absorbance reading at $600 \mathrm{~nm}$ until the optical density reached about 1 . Pellets were collected after 
centrifugation, then suspended in sterile double-distilled $\mathrm{H}_{2} \mathrm{O}$ to obtain a final $E$. coli cell suspension of $2.0 \mathrm{mg} / \mathrm{mL}$ and $S$. aureus cell suspension of $0.8 \mathrm{mg} / \mathrm{mL}$. Adult female mosquitoes were anesthetized on ice for $5 \mathrm{~min}$ and then gradually injected with $2 \mu \mathrm{L}$ of bacterial suspension. The injected adult female mosquitoes were divided into three groups of 30 mosquitoes each for use in the follow-up experiment.

Beauveria bassiana (strain 242) was obtained from the microbial bank of Hainan University. Beauveria bassiana was cultured on potato glucose agar plates at $28{ }^{\circ} \mathrm{C}$ for 10 days until the plate was covered with hyphae and conidia. Then eight to 10 fungal colonies were added to $100 \mathrm{ml}$ potato dextrose broth and cultured at $28{ }^{\circ} \mathrm{C}$, 240 r.p.m. for several days. After the medium was turbid, it was filtered through aseptic neutral filter paper and the filtrate aspirated into aseptic 1.5-ml Eppendorf tubes for centrifugation. The harvested spores were suspended in $0.05 \%$ Tween 80 . Fungal spores were counted under a hemocytometer with an inverted microscope and diluted to $2.65 \times 10^{6}$ spores $/ \mathrm{mL}$ with $0.05 \%$ Tween 80 . An appropriate amount of spore suspension was dipped into a ground aseptic capillary tube, which was used to pierce the ventral tip of the frozen anesthetized adult female mosquitoes, to infect them with $B$. bassiana spores. The infected adult female mosquitoes were divided into three groups comprising 30 mosquitoes each, which were used in the follow-up experiment.

For the tissue injury experiment, the thorax of freezeanesthetized adult female mosquitoes was punctured with a ground aseptic capillary tube to cause effective physical damage. The adult female mosquitoes were divided into three groups comprising 10 mosquitoes each. Three independent repeated experiments were carried out for each of the above treatments.

\section{RNA extraction and quantitative polymerase chain reaction}

To analyze the spatiotemporal expression profiles of $A e$ CLIPB15 (GenBank accession number AAEL014349) and Ae-CLIPB22 (GenBank accession number AAEL008668) and their expression profiles after microbial infection and tissue injury, the total RNA was extracted from the different tissues of female adult mosquitoes (those of the thorax, fat body and other parts), and from different developmental stages, as well as from adult female mosquitoes after microbial infection and tissue injury. Total RNA was extracted from adult mosquitoes for each of the three independent repeats. Quantitative real-time polymerase chain reaction (qPCR) was performed as described previously [37] in a LightCycler 480 system (Roche Applied Science, Mannheim, Germany) using SYBR Green Master I (Roche) according to the manufacturer's instructions, with the following cycling conditions: initial denaturation at $95{ }^{\circ} \mathrm{C}$ for $30 \mathrm{~s}$ followed by 40 cycles of $95{ }^{\circ} \mathrm{C}$ for $5 \mathrm{~s}$, and $60{ }^{\circ} \mathrm{C}$ for $30 \mathrm{~s}$. Primers (forward, 5'-CTGTAAGGTCCTGTGAAT ACG-3'; reverse, 5'-GGTTTATCAGGGAGTTCA CC-3') were used to amplify the 109-bp DNA fragment of Ae-CLIPB15. Primers (forward, 5'-GATCCTGTC AAAGGCTTCC-3'; reverse, 5'-GTACTGTCAGTGCGT ATTGG-3') were used to amplify the 236-bp DNA fragment of Ae-aaCLIP22. The Ae. aegypti ribosomal protein S17 gene (GenBank accession number AAEL025999) was used as a reference gene. Messenger RNA (mRNA) expression was quantified using the comparative cross threshold (Ct; number of PCR cycles required for the fluorescent signal to cross the signal threshold) method. The relative $2^{-\Delta \Delta c t}$ method was used to analyze the relative gene expression data [38].

\section{Double-stranded RNA preparation}

Total RNA was extracted from adult mosquitoes with the SPARKeasy Cell RNA Kit (Sparkjade) and then subjected to qPCR using the PrimeScript RT Reagent Kit with the genomic DNA Eraser Kit (TaKaRa). Primers (forward, 5'-GGAACTCCCTGATAAACC-3'; reverse, 5'-AAC GCACATATTCTAACG-3') were used to amplify the fragment of $A e-C L I P B 15$ from the cDNA. Primers (forward, 5'-TGTGGCACTGCTTCCGATTT-3'; reverse, 5'-GAGTATTGCGTAGTCCTTGTA-3') were used to amplify the fragment of $A e-C L I P B 22$ from the cDNA. The $\beta$-glucuronidase gene (gus) (KY848224), a bacterial gene specific to E. coli, was used as the negative control, as reported previously [39]. The PCR products were collected and purified. The gene fragments were cloned into PMD19-T (TaKaRa), and NotI and XhoI restriction enzymes used to excise target fragments from PMD19$\mathrm{T}$, which were then ligated into plasmid pL4440. The recombinant plasmid was transformed into competent cells of the RNase-III-deficient E. coli strain HT115(DE3), following a previously described method [39]. The cells were grown in $2 \times$ Luria-Bertani medium (10 g/l tryptone, $5 \mathrm{~g} / \mathrm{l}$ yeast extract, $10 \mathrm{~g} / \mathrm{l} \mathrm{NaCl}$ ) containing ampicillin and tetracycline at $37^{\circ} \mathrm{C}$ for $12-14 \mathrm{~h}$. The bacterial solution was grown until optical density measured at a wavelength of $600 \mathrm{~nm}$ reached 0.5. Isopropyl- $\beta-\mathrm{D}$ thiogalactopyranoside was added to a final concentration of $0.6 \mathrm{mM}$ to induce T7 polymerase activity. The expressed double-stranded RNA (dsRNA) was extracted and confirmed by electrophoresis on $1 \%$ agarose gel.

\section{RNA interference}

The adult mosquitoes were collected 3-5 days after hatching and $24 \mathrm{~h}$ after they had fed on sugar water. A moderate number of mosquitoes were placed in a 
refrigerator at $-20{ }^{\circ} \mathrm{C}$ for a few minutes. The frozen mosquitoes were then put on ice and injected with purified dsRNA by using a manual microinjection device (Eppendorf, Hamburg, Germany). Meanwhile, four groups of females were injected in the thorax with $2 \mu \mathrm{l}$ of one of the following: the dsRNA of gus (control group); diethyl pyrocarbonate (DEPC)-treated water (control group); dsRNA of $A e-C L I P B 15$ (dsAe-CLIPB15); dsRNA of Ae-CLIPB22 (dsAe-CLIPB22). Thirty female adults were injected in each group, and all the experiments were repeated three times. After injection, the mosquitoes were transferred to mosquito cages and collected $24 \mathrm{~h}$ later for the preparation of RNA. RNA interference (RNAi) efficiency was verified by qPCR.

\section{Mosquito survival assays and analysis of transcription factor expression}

Twenty-four hours after dsRNA injection, the four groups of mosquitoes were infected with either E. coli, S. aureus, or B. bassiana. Twenty adults from each group were used in the survival assays, which were carried out at 1-day intervals during the following week. Three independent biological repeat experiments were carried out for each treatment. To explore whether the expression of transcription factors Ae-REL1 (GenBank accession number AAEL012164) and Ae-REL2 (GenBank accession number AAEL007624) would be affected when $A e-C L I P B 15$ and Ae-CLIPB22 were knocked down in the adults $24 \mathrm{~h}$ after dsRNA injection, four groups of mosquitoes were infected with one of the above bacteria. After $24 \mathrm{~h}$, total RNA was extracted for three independent recombination experiments. Primers (forward, 5'ATAGGCGAGATCAACATCAGCAGC-3'; reverse, 5'-CGTTGCTGTTCCTGCTTCATATCG-3') were used to amplify the fragment of Ae-REL1. Primers (forward, 5'-TTTGAATGTGCTGTTGGGTC-3'; reverse, 5'-GAA TGTTGTTTCCGTGCTTA-3') were used to amplify the fragment of $A e-R E L 2$ using cDNA as a template. All the analyses were repeated three times.

\section{PO activity assay}

To determine PO activity, adult mosquitoes were injected with dsRNA 2 days prior to the experiment. The thoraces of ten mosquitoes from each group were added to a $1.5-\mathrm{ml}$ Eppendorf tube with $200 \mu \mathrm{l}$ HEPES buffer $(50 \mathrm{mmol} / \mathrm{L})$, and then crushed with a grinding machine and centrifuged at 12,000 r.p.m. for $20 \mathrm{~min}$ at $4{ }^{\circ} \mathrm{C}$ to collect the hemolymph. A total volume of $75 \mu \mathrm{l}$ tissue fluid containing hemolymph and $125 \mu \mathrm{l}$ of L-dopamine $(8 \mathrm{mmol} / \mathrm{L}$ in $50 \mathrm{mmol} / \mathrm{L}$ HEPES, $\mathrm{pH} 8.0)$ were added to a 96-well plate and the absorption at $490 \mathrm{~nm}$ was recorded every $10 \mathrm{~s}$ for $20 \mathrm{~min}$ on a microplate reader (RNE90002; Reagen, China). One unit of PO activity is defined as the amount of enzyme yielding $\mathrm{PO}$ that produces an increase of 0.001 absorbance units/min [40]. Each treatment was performed as three independent biological replications.

\section{Statistical analyses}

All the statistical analyses were performed using GraphPad Prism version 6.02 (GraphPad Software). A $t$-test was used to determine significant differences $(P<0.05)$ in the levels of mRNA and PO between the control and treatment groups. GraphPad Prism software was used to analyze the mosquito survival curves.

\section{Results}

Multiple amino acid sequence alignment

Multiple amino acid sequence alignment showed that Ae. aegypti CLIPB15 is similar to An. gambiae CLIPB15 (percent identity 49.16\%), Bombyx mori PPAE (percent identity $37.10 \%$ ) and Drosophila melanogaster GRASS (percent identity $34.20 \%$ ); and that Ae-CLIPB22 is similar to Bombyx mori PPAE (percent identity $34.53 \%$ ) and $A n$. gambiae CLIPB15 (percent identity 34.33\%) (Fig. 1).

\section{Spatiotemporal expression profiles of $A e-C L I P B 15$ and $A e-C L I P B 22$}

Spatiotemporal expression profiles of $A e-C L I P B 15$ and $A e-C L I P B 22$ were analyzed by qPCR. The transcript expression levels of these genes were investigated in 11 different developmental stages including the egg, larval, pupal and adult stages, and in tissues of six different parts of the adult mosquito (legs, thorax, fat body, midgut, ovary, and Malpighian tubule). The Ae-CLIPB15 transcript expression levels in the fourth-instar larvae were significantly higher than in the other larval stages [e.g. first-instar vs fourth-instar, $t$-test, $t_{(22)}=11.20$, $P<0.0001]$, and those in adult male mosquitoes were significantly higher than in first-instar larvae [first-instar vs male adult, $t$-test, $t_{(22)}=20.00, P<0.0001$ ] (Fig. 2a) and in adult females. The transcript expression levels of $\mathrm{Ae}$ CLIPB22 had significantly increased by the fourth-instar larval stage compared to the first-instar [first-instar vs fourth-instar, $t$-test, $\left.t_{(22)}=17.67, P<0.0001\right]$ and the higher level was maintained in the pupal and adult female mosquito stages. However, the transcript expression level of this gene decreased significantly in adult male mosquitoes [first-instar vs male adult, $t$-test, $t_{(22)}=1.986$, $P=0.3120$ ] (Fig. 2b). The expression of both genes was lowest in the eggs.

$A e-C L I P B 15$ and $A e-C L I P B 22$ were expressed in different tissues of adult female mosquitoes. The transcript expression levels of Ae-CLIPB15 in the thorax [legs vs thorax, $t$-test, $\left.t_{(12)}=11.34, P<0.0001\right]$ and fat body [legs vs fat body, $t$-test, $\left.t_{(12)}=16.80, P<0.0001\right]$ were significantly higher than in the other tissues (Fig. 2c). 


\begin{tabular}{|c|c|}
\hline $\begin{array}{l}\text { Tm-PPAF } \\
\text { Ms-HP21 }\end{array}$ & 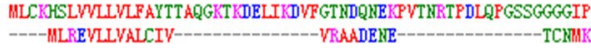 \\
\hline $\mathrm{Dm}$-GRASS & \\
\hline A $-\mathrm{PPAF} 1$ & ---MRFAVSKLVTLATVTLSTQLPQPVPEQTGPVWDITT---------QCSIP \\
\hline Bm-PPAE & 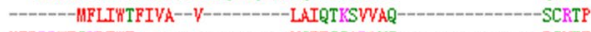 \\
\hline he-CLIPB22 & 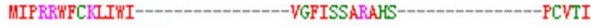 \\
\hline he-CLIPB15 & 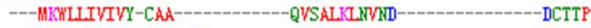 \\
\hline AECLIPB15 & --MRRLVCLIVSWCSLVPLG---ATVGQSLISGD---- \\
\hline $\mathrm{Tm}-\mathrm{PPAF}$ & G-TGSCTCVPYYLCHYGSYRTHGEGVIDIRI-------KEGPCE-------KYIDVC \\
\hline Ms-HP21 & 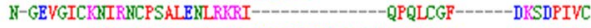 \\
\hline Dm-GRASS & -----MPFSSCRTIEERLTEAQKAGQKVPADYASYLQKALCGE-----FNGVRИRC \\
\hline ha-PPAF1 & RESWYGTCTLPIDCPAYATIMRPED----V/SSVGRLSFLKTQCSS------AGTDGIC \\
\hline Bm-PPAE & H-GLYGICVSVIRCQALLLILNRTQR----RT-QQDEKFLRDSQCGT-----KYSVPAVC \\
\hline Ae-CLIPB22 & 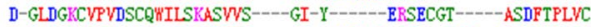 \\
\hline Ae-CLIPB15 & C-GKP'GKCVPVRSCEYGLSRLRRPN----AT-YEDTLYLQSSICGELP---DKPYFPLTC \\
\hline A 6 CLIPB15 & S-GTAGTCEPVKACSYYRKILKSPD----FS-HYDTTYLDTLKCGDLMVPMRKKPIPLUC \\
\hline & * $*$ * $\quad *$ \\
\hline $\mathrm{Tm}_{\mathrm{m}} \mathrm{PPAF}$ & CDKGSESDE----_-_- \\
\hline Ms-KrP21 & CVESVTTPAPTQ-------PPIATTTKRPQVTTTTEYEPPLYEYETVDRQGSGCPPIDAN \\
\hline Dn-GRASS & CPSARIQHY--- \\
\hline Aa-PPAF1 & 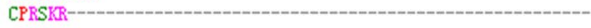 \\
\hline $\mathrm{Bm}-\mathrm{PPAE}$ & CPCHAADGQQGRCVINSCPYVLQLLRPPYEAN--------LAY----VRGSVCQGSEQQ \\
\hline he-CLIPB22 & CPR'R'RH-- \\
\hline he-CLIPB15 & CPALV--- \\
\hline AGCLIPB15 & CPKSSH--- \\
\hline & $*$ \\
\hline $\mathrm{Tm}-\mathrm{PPAF}$ & ------------P-----ITPTPS----------------PVKKSGCGHRPP DGVGRRIT \\
\hline Ms-HP21 & ----LTSPKI GRKA'WDKCLEYQEKLVYPCEKSFSLSLRDAMERKYKCH----KWADDLII \\
\hline $\mathrm{Dm}$-GRASS & - \\
\hline A - PPAF1 & ---1 YQTP---TLNETLPKRVRHKTTRVH-SRFGH--DDDVCG-Y--QSFVPKIR \\
\hline Bm-PPAE & SICCVTAPQSTAV----TTTPRPKRVHACQSEMTATPPKP--EGKCCGRD--IAVGDKIV \\
\hline he-CLIPB22 & - \\
\hline he-CLIPB15 & -1---PTDCG-L--IDFTKRIV \\
\hline AG CLIPB15 & ----SPTCG-A--QQLADRIY \\
\hline & $*$ \\
\hline $\mathrm{Tm}-\mathrm{PPAF}$ & 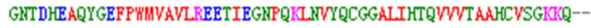 \\
\hline Ms-YP21 & G--GQHASRREPPHHALLGYGEE-----PDVQWLGGGLISEMPILTAGHCISSRDI-- \\
\hline Im-GRASS & 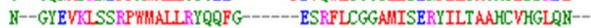 \\
\hline Aa-PPAF1 & G--GEIARIDEPPWHAMLLYELKD----SKKTVHGCGGALISKYTVITAHHCVT GKDYDH \\
\hline $\mathrm{Bm}-\mathrm{PPAE}$ & G--GAPASIDSYPWLVYIEYVRL-----ERTMLLCGGALISGKYYLTAGHCVKGGILDY \\
\hline Ae-CLIPB22 & --TDSPPWVYSIVYRVKW----KIFSQRCTGSLINSQYALTVAHCIADFSP-Y \\
\hline Ae-CLIPB15 & 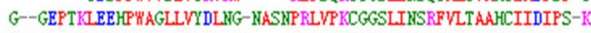 \\
\hline AFCLIPB15 & P--GEETERGALPWHALLFYNVGR-----MRTYPKCGGALISERYVITAAHCTVDKP--Y \\
\hline
\end{tabular}

$\begin{array}{ll}60 & \text { Tm-PPAP } \\ 26 & \text { Ms-HP21 } \\ 0 & \text { Dm-GRASS } \\ 42 & \text { As-PPAF1 } \\ 27 & \text { Bm-PPAE } \\ 29 & \text { Ae-CLIPB22 } \\ 29 & \text { Ae-CLIPB15 } \\ 34 & \text { A-CLIPB15 }\end{array}$

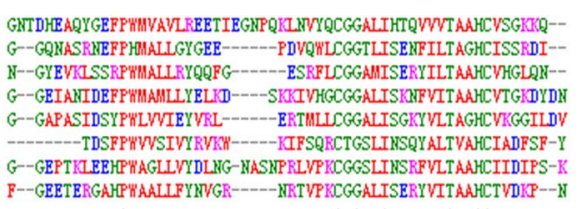

A. - CLIPB15

$102 \quad \mathrm{Tm}-\mathrm{PPAP}$

$\begin{array}{ll}65 & M s-H P 21 \\ 46 & \mathrm{Dm}-\mathrm{GRHSS}\end{array}$

Dm-GRASS
Aa-PPAF1

$\mathrm{Bm}-\mathrm{PPAB}$

Ahe-CLIPB22

he-CLIPB15

AECLIPB15

$\mathrm{Im}_{\mathrm{m}}-\mathrm{PPAP}$

Ms-HP21

Dm-GRASS

ha-PPdF1

$\mathrm{Bm}-\mathrm{PPAB}$

Ae-CLIPB22

he-CLIPB15

As-CLTPB15

Tm-PPAF

Ms-HP21

Dm-GRASS

Aa-PPAP 1

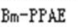

Ae-CLIPB22

he-CLIPB15

Tm-PPAP

Ms-HP21

Dm-GRaSS

Aa-PPAF 1

$\mathrm{Bm}-\mathrm{PP}$ kE

He-CLIPB22

Ae-CLIPB15

AE CLIPB15

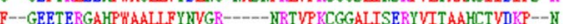

$$
* *:: * \quad: *, * *
$$

---PKIRAGEWDTQTK---_---KRLYPHQDREVESITVHPQYYAGA--LFKDY

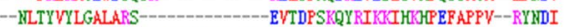
--DLYEIRLGEHEIST-EEDCRQQ-GRKKRCAPPWNVGIENTLTHEKYDARH--IMFDI KGPLKYVRLREYKVYD-DPDCVIR-HRFQDCSEEKIDSEPVRIITHPEYDPYFRHKYYDI -GTPKTVRLGEYKTTKPGRDCVSVSAGGTDCTDPLVIIGIEKTIPHPDYQPYHFLRKODI -WKPYSVRVIRD--------------TT---YKDYATLRSIVHPSYKRPRLLNKDHDY

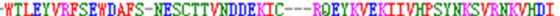

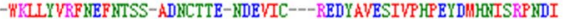

AMLPLKTPVDIAENVNYVLLPPQGTNV----DHARCYASGWGKDGVRA----BGRYQVIL ALVELERNVPLDEWLYPACLUUGDETA----DDRVWATGWGLTEYKA----SSGARIL ALLKLIRSVYPFGKTKPICLPITDELKEKAEQISTYFVTGWGTTE-------NGSSSDVL ALIEINQVPSYTDFLRHCCLPEAKLDN-GVASGKTFSVSGHGRTDTFRQQLGMIALSPIK GLIRLOSIAPFTDFIRPICLPSTDYTV-KIPSIF ALTVAGHRRYLPFDH--GTVRSSKIK SLLKLVIKVYFDDYVQPICLTRERDQHSTLYEGQMLTIFSKGPTE-------AGQISSQK

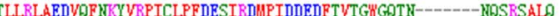
***

KKTDLPWPRDICQEALRSTRLGKHFELVISPICAGGE-PKTDTCKGDGGSPLYCPI-QKVYLNKFSTFECILQYPPHRLISQGPDVISQHCY GDRSQSKDTCQGDSGGPLRIKHK-LQANYPLQPRSACSQAYR-----RAVPLQLCVGGG-DLQDSCKGDSGGPLQAPAQYL LKVVLPYVEPEQCRRVFR----AQQLEIGPGQLCAGGE-KAKDTCGGDSGSPUMFYD---

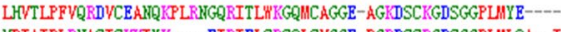
IPIAIPLRHASICKUIYK----EIRIRLSRSQLCVGGE-PGRDSCRGDSGGPUILQA--I LHVDLIGKTLDVCNEKTS----IANVTLVDTQLCVGGE-KGKDSCKGDSGGPIMRL-KHVRLPGLEHEACHSVY'----VARYTLSDKDLCIGGL-MGSDSCRGDSGGPIIRE---LCIGGL-IGSDSCRGDSGGPLI
$* * * * * * * * *$

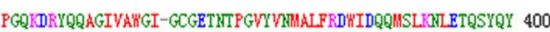
-KIXCMW'LIIGVTSPGK-ACGPIGEPGIYTKVSHYIPWIESWWY------ 413 GRYAPKNVEFGIVSQGWTCGQISLPGLYTRVGEYVQWITDTHASIGL------ 335 -VKAGAWVLTGIVSLGVRDCGTEGIPGVTTVVRQYLDWTKATAQ--------- 405 --HSKKYEAVGIVSPGPEKCGQIDIPGVYTYVYEYLPYIQRTIEP--------- 441 DSMTPRYYQYGLVYLGPEKCGG-TIPGIYVKLLDYLEWIEATVDEV/ --VITVWYQYGYVSPGNXYCGTEGRPGIYTDYSKYLKWTEKRAHAL HCPSDYA-- 366 - VRGCUPJ TOVPPG

-VRGGHPLIGWSPGARPCGTQNLPGVYTNYAKYLDWHETVMFVERYL----- 364

Fig. 1 Multiple amino acid sequence alignment of Aedes aegypti (Ae) clip domain serine proteases (CLIPS) (Ae-CLIPB15 and Ae-CLIPB22) with CLIPS from other insect species: Anopheles gambiae CLIPB15 (Ag-CLIPB15, AGAP009844-PA); Drosophila melanogaster GRASS (Dm-GRASS, Dmel_CG5896); Manduca sexta HP21 (Ms-HP21, AAV91019.1); Bombyx mori prophenoloxidase-activating enzyme (Bm-PPAE, NP_001036832.1); Aedes albopictus prophenoloxidase activating factor (Aa-PPAF1,XP_029722923.1). These sequences were aligned by the Clustal Omega program with default settings. Asterisks indicate 100\% homology, colons indicate $90 \%$ homology, points indicate $80 \%$ homology

Transcripts of $A e-C L I P B 22$ were most abundant in the midgut [legs vs midgut, $t$-test, $t_{(12)}=8.583, P<0.0001$ ], compared to the other types of tissues (Fig. 2d).

\section{Microbial infection and tissue injury can induce the expression of $A e-C L I P B 15$ and $A e-C L I P B 22$}

To determine whether Ae-CLIPB15 and Ae-CLIPB22 respond to microbial challenge in Ae. aegypti, we first measured their expression levels after bacterial and fungal infection. Infection with the Gram-positive bacterium $S$. aureus and with the Gram-negative bacterium E. coli induced up-regulation of $A e-C L I P B 15$ [DEPC vs $E$. coli, $t$-test, $t_{(4)}=28.66, P<0.0001 ; D E P C$ vs $S$. aureus, $t$-test, $\left.t_{(4)}=15.71, P<0.0001\right]$ and $A e-C L I P B 22$ (DEPC vs $E$. coli, $t$-test, $t_{(4)}=14.36, P=0.0002$; DEPC vs $S$. aureus, $t$-test, $t_{(4)}=26.55, P<0.0001$ ] (Fig. 3a, b). Infection with the fungus $B$. bassiana could induce up-regulation of Ae-CLIPB15 [DEPC vs B. bassiana, $t$-test, $t_{(4)}=26.99$,
$P<0.0001$ ] and $A e-C L I P B 22$ [DEPC vs $B$. bassiana, $t$-test, $t_{(4)}=6.109, P=0.0036$ ] (Fig. 3c). Similarly, the expression of $A e-C L I P B 15$ [control vs $6 \mathrm{~h}, t$-test, $t_{(6)}=37.29$, $P<0.0001$ ] and $A e-C L I P B 22$ [control vs $6 \mathrm{~h}, t$-test, $t_{(6)}=13.87, P=0.0002$ ] was up-regulated $6 \mathrm{~h}$ after $A e$. aegypti mosquitoes were exposed to superficial physical damage (Fig. 3d). Ae-CLIPB15 and Ae-CLIPB22 showed different responses to bacterial and fungal infection, and played a specific role in regulating wound healing in the mosquitoes.

\section{Knockdown of $A e-C L I P B 15$ and $A e-C L I P B 22$ resulted in higher susceptibility to bacterial and fungal infections}

To confirm whether Ae-CLIPB15 and Ae-CLIPB22 contribute to the defense of Ae. aegypti mosquitoes against bacterial and fungal infection, we injected dsRNA into the mosquito thorax and monitored the survival of the 

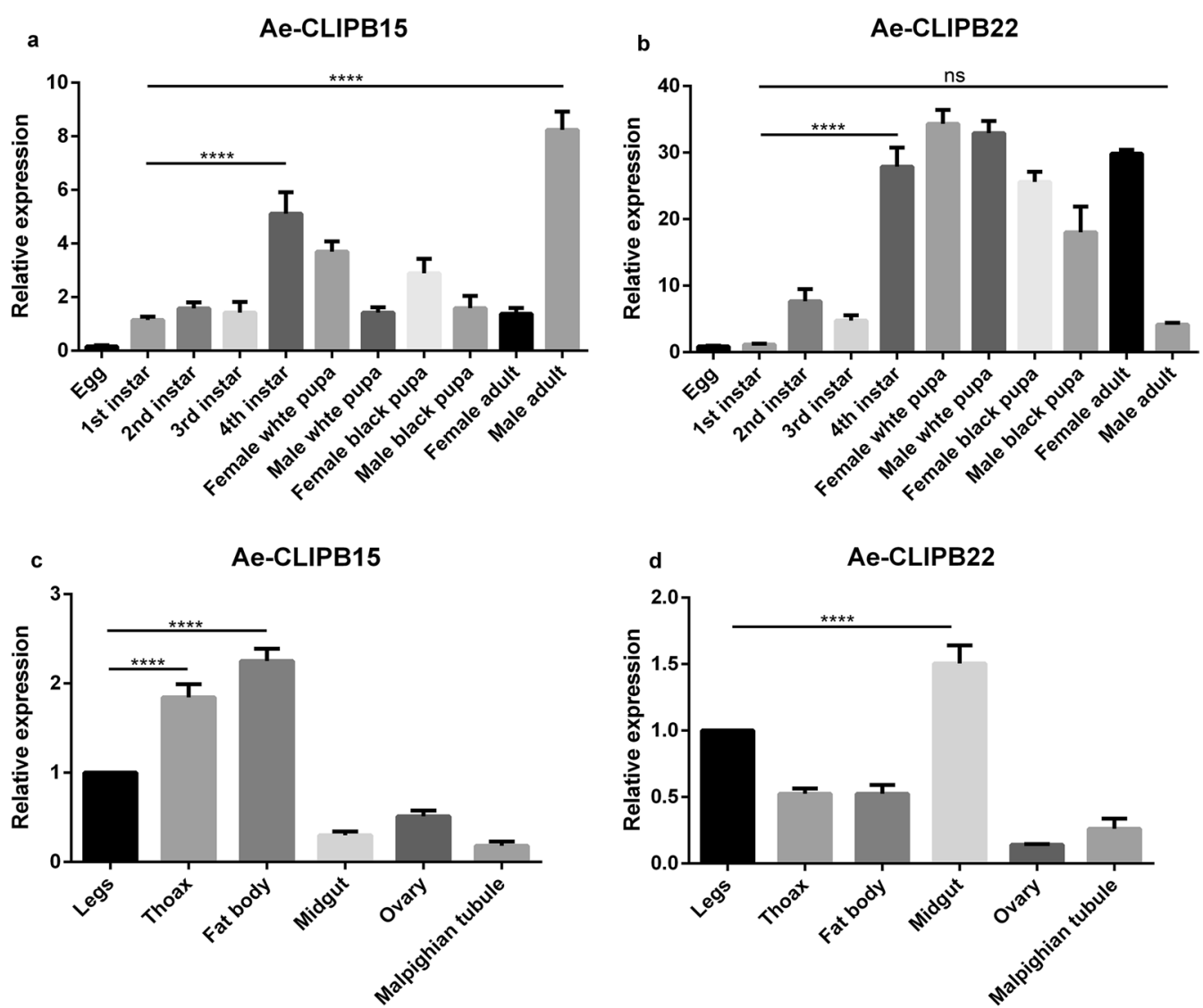

Fig. 2 a-d Spatiotemporal expression profiles of Ae-CLIPB15 and Ae-CLIPB22. Relative expression levels of Ae-CLIPB15 (a) and Ae-CLIPB22 (b) at 11 developmental stages from egg to adult. Relative expression levels of Ae-CLIPB15 (c) and Ae-CLIPB22 (d) in six different types of tissues (thorax, legs, fat body, midgut, ovary, and Malpighian tubule). The statistical analyses were performed using two-way ANOVA in GraphPad software; data are presented as means $\pm \mathrm{SD}(n=3) .{ }^{* * *} P<0.001$; $n$ s not significantly different. For abbreviations, see Fig. 1

female adults after infection. At $24 \mathrm{~h}$ post-infection, the relative mRNA expression levels of Ae-CLIPB15 [GUS vs dsAe-CLIPB15, $t$-test, $\left.t_{(6)}=12.76, P<0.0001\right]$ and $A e$ CLIPB22 [GUS vs dsAe-CLIPB22, $t$-test, $t_{(6)}=14.80$, $P<0.0001]$ were significantly decreased, indicating successful knockdown of these two genes (Figs. 4a, 5a). The female adults were also infected with bacteria and fungi after successful $A e-C L I P B 15$ and $A e-C L I P B 22$ knockdown. Knockdown of Ae-CLIPB15 [dsGUS +E. coli vs dsAe-CLIPB15 $+E$. coli, $t$-test, $t_{(12)}=3.251, P=0.0314$; $\mathrm{dsGUS}+S$. aureus vs dsAe-CLIPB15 $+S$. aureus, $t$-test, $\left.t_{(12)}=5.547, P=0.0149\right]$ and Ae-CLIPB22 [dsGUS $+E$. coli vs dsAe-CLIPB22 $+E$. coli, $t$-test, $t_{(12)}=3.333$, $P=0.0207$; dsGUS $+S$. aureus vs dsAe-CLIPB $22+S$. aureus, $t$-test, $\left.t_{(12)}=4.803, P=0.0187\right]$ resulted in a significant decrease in the survival rate of mosquitoes infected with E. coli (Figs. 4b, 5b) and S. aureus (Figs. 4c, 5c) compared with the control groups. The survival rate of mosquitoes infected with $B$. bassiana [dsGUS $+B$. bassiana vs dsAe-CLIPB15 + B. bassiana, $t$-test, $t_{(12)}=8.71$,
$P=0.0074 ;$ dsGUS $+B$. bassiana vs dsAe-CLIPB22 $+B$. bassiana, $t$-test, $\left.t_{(12)}=7.251, P=0.0102\right]$ was also significantly lower than that of the control group (Figs. 4d, 5d). In summary, these results show that both of these genes are implicated in immune reactions triggered in response to bacterial and fungal infection.

\section{Knockdown of $A e-C L I P B 15$ and $A e-C L I P B 22$ resulted in different regulation of transcription factors}

To confirm whether $A e-C L I P B 15$ and $A e-C L I P B 22$ can regulate the Toll pathway and IMD pathway of the innate immune response of Ae. aegypti, the expression levels of NF-kB transcription factors REL1 and $R E L 2$ in the Toll pathway and IMD pathway were investigated in mosquitoes infected with Gram-negative $E$. coli. Ae-CLIPB15 and Ae-CLIPB22 were knocked down by injected dsRNA. The mosquitoes were infected with E. coli and $S$. aureus $24 \mathrm{~h}$ after dsRNA injection. At $12 \mathrm{~h}$ post-infection, total RNA was extracted and qPCR performed. The knockdown of Ae-CLIPB15 [dsGUS +E. coli 

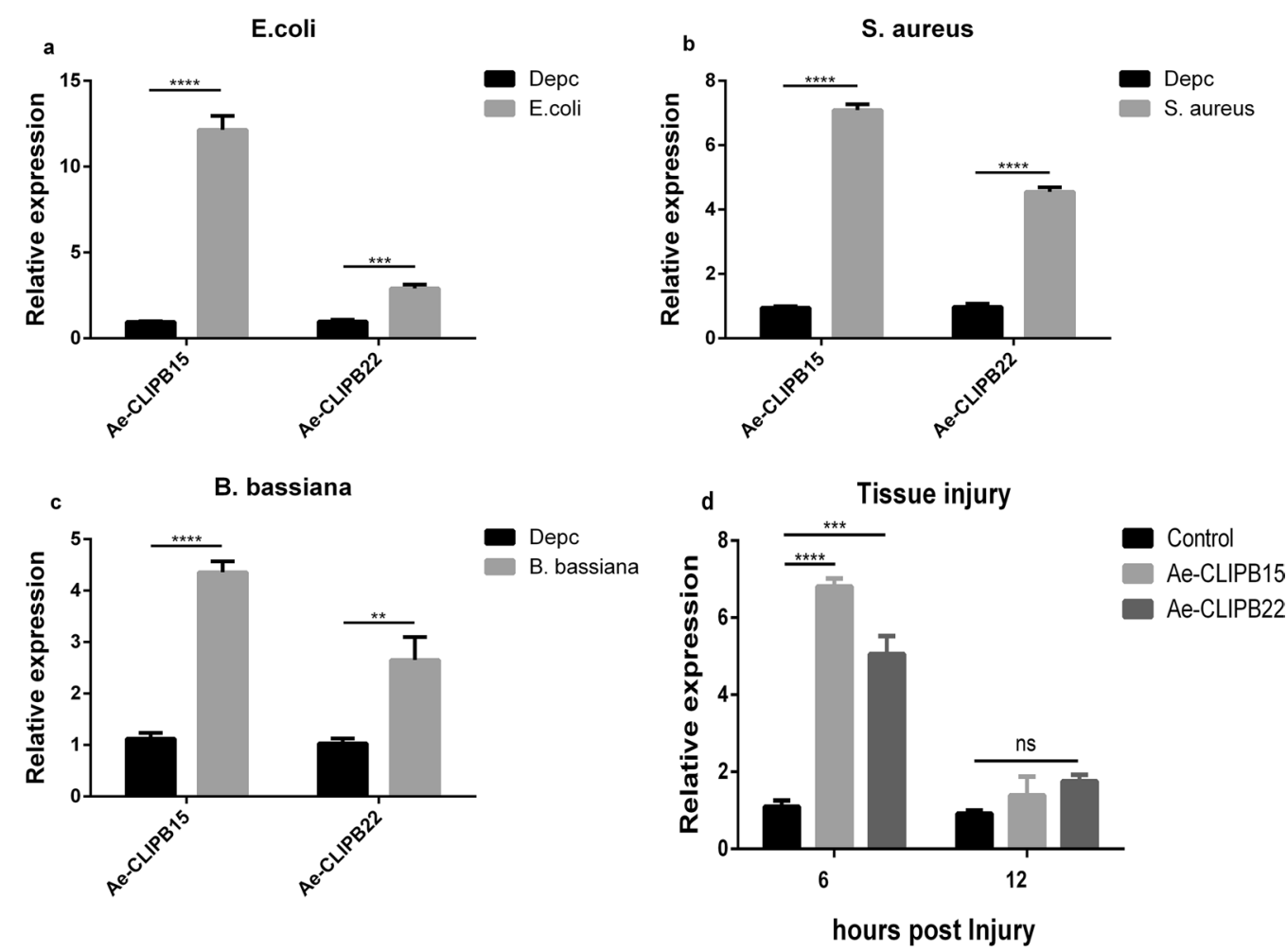

Fig. 3 Relative expression levels of Ae-CLIPB15 and Ae-CLIPB22 in adult mosquitoes following infection with Escherichia coli (a), Staphylococcus aureus (b) and Beauveria bassiana (c), and after physical injury (d). The control groups were injected with diethyl pyrocarbonate (Depc)-treated water. The abundances of messenger RNA (mRNA) of Ae-CLIPB15 and Ae-CLIPB22 were determined by quantitative real-time polymerase chain reaction (qPCR). The expression of these genes in the infection group was compared to that in the control group at $24 \mathrm{~h}$ post-infection. In the physical damage experiment, the control group was not injured. The mRNA abundance for Ae-CLIPB15 and Ae-CLIPB22 was determined by qPCR, and the mRNA expression levels of Ae-CLIPB15 and Ae-CLIPB22 in the injured groups were compared with those in the control group at $6 \mathrm{~h}$ and $12 \mathrm{~h}$ post-injury. The expression profiles were compared using two-way ANOVA in GraphPad software; data are presented as means $\pm S D, n=3$. ${ }^{* *} P<0.01$, ${ }^{* *} P<0.001$, ${ }^{* * * *} P<0.001$. For other abbreviations, see Fig. 1

vs dsAe-CLIPB15 $+E$. coli, $t$-test, $\left.t_{(8)}=10.81, P<0.0001\right]$ and Ae-CLIPB22 [dsGUS +E. coli vs dsAe-CLIPB22 +E. coli, $t$-test, $\left.t_{(8)}=12.19, P<0.0001\right]$ resulted in a significant decrease in the transcript expression levels of NF- $\kappa B$ transcription factor REL2 in the IMD pathway after the female adults were infected by the Gram-negative bacteria $E$. coli. In contrast, the expression of NF- $\mathrm{kB}$ transcription factor $R E L 1$ in the Toll pathway was not significantly different from that in the control group (Fig. 6a). Interestingly, when the female adults were infected with the Gram-positive bacteria $S$. aureus, the expression of NF- $\mathrm{kB}$ transcription factor REL1 in the Toll pathway was significantly decreased in the Ae-CLIPB15 knockdown adults [dsGUS $+S$. aureus vs dsAe-CLIPB15 $+S$. aureus, $t$-test, $t_{(8)}=3.233, P=0.0298$ ] but significantly increased in $A e-C L I P B 22$ knockdown adults [dsGUS $+S$. aureus vs dsAe-CLIPB22 $+S$. aureus, $t$-test, $t_{(8)}=12.36$, $P<0.0005]$. The expression of NF-kB transcription factor $R E L 2$ in the IMD pathway was significantly decreased in Ae-CLIPB15 knockdown adults [dsGUS + S. aureus vs
dsAe-CLIPB15 $+S$. aureus, $t$-test, $\left.t_{(8)}=6.411, P=0.0005\right]$ and $A e-C L I P B 22$ knockdown adults [dsGUS $+S$. aureus vs dsAe-CLIPB22 $+S$. aureus, $t$-test, $t_{(8)}=15.83$, $P<0.0001$ ] (Fig. 6b). Although the expression of REL1 was not affected by the knockdown of either Ae-CLIPB15 or Ae-CLIPB22 in mosquitoes infected with E. coli, the knockdown of these genes did affect its expression in the mosquitoes infected with $S$. aureus. In short, these results show that both $A e-C L I P B 15$ and $A e-C L I P B 22$ are involved in the regulation of the expression of REL1 and REL2 in the Toll pathway and the IMD pathway in the innate immune response of Ae. aegypti, and suggest that these genes play different roles in the regulation of innate immune pathways. However, the differences in the expression level of REL2 do not necessarily mean that $A e-C L I P B 15$ and $A e-C L I P B 22$ directly regulate the IMD pathway, as innate immune pathways may interact with each other. Thus, the change in the expression of REL2 may have been caused by an indirect effect. In summary, further experiments are needed to examine this. 

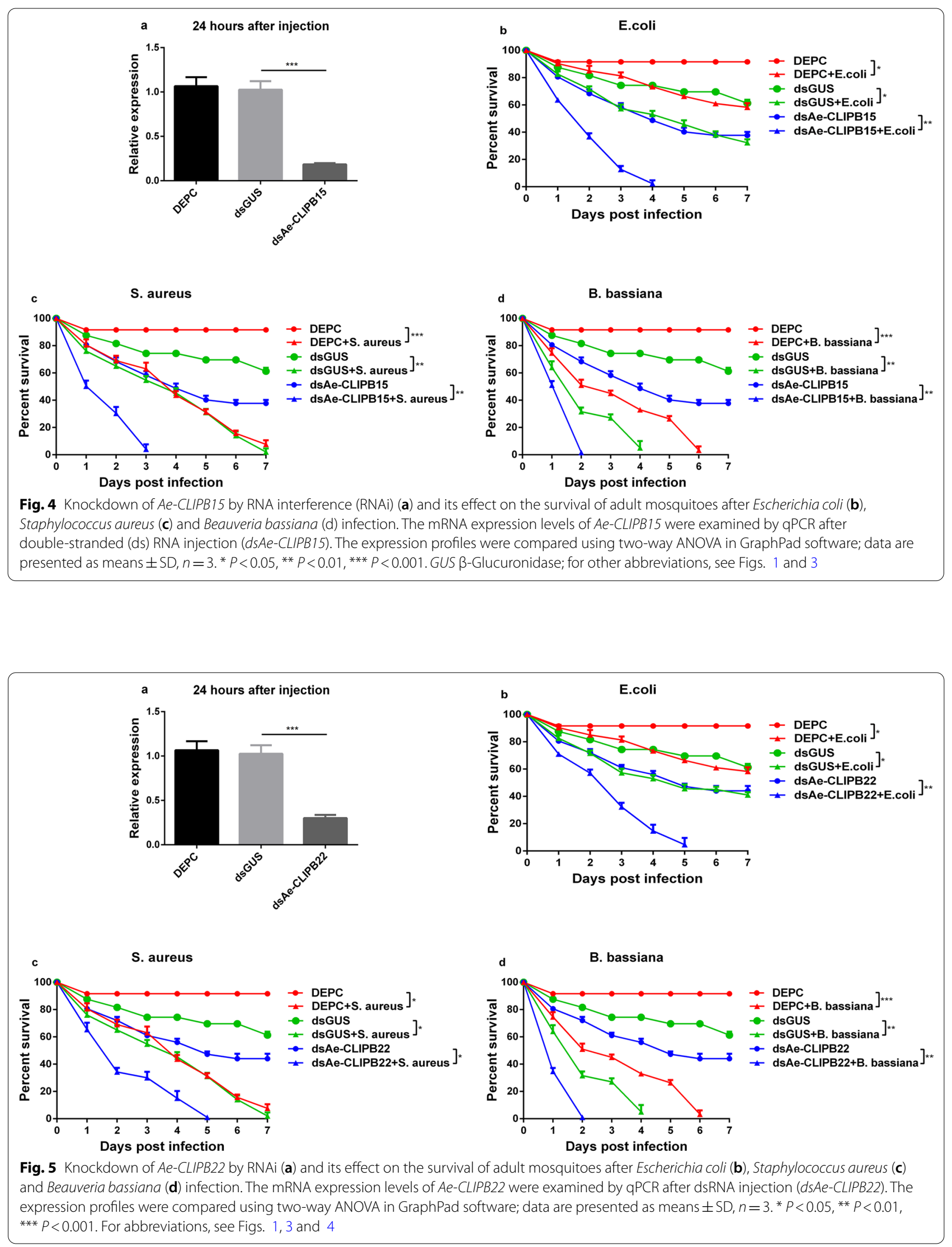


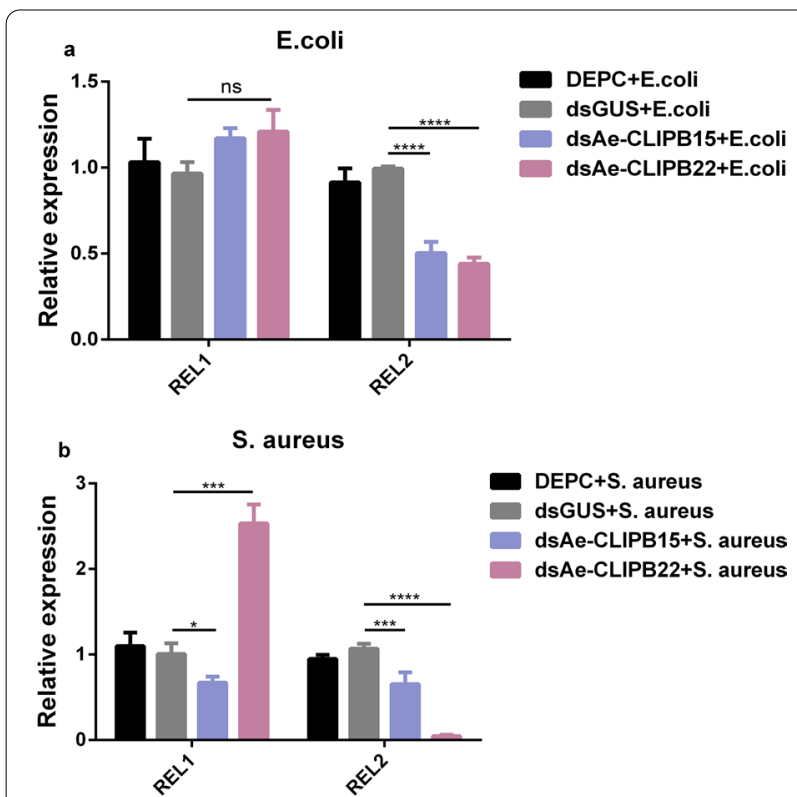

Fig. 6 Knockdown of Ae-CLIPB15 and Ae-CLIPB22 by RNAi and the effect on the expression levels of NF-kB transcription factors REL 1 (a) and REL2 (b) in the Toll pathway and IMD pathway of mosquitoes after bacterial infection. The relative expression levels of REL 1 and REL2 were examined by qPCR after bacterial infection. The expression profiles were compared using two-way ANOVA in GraphPad software; data are presented as means $\pm \mathrm{SD}, n=3 .{ }^{*} P<0.05$, ${ }^{* * *} P<0.001$, **** $P<0.001$. For other abbreviations, see Figs. $1,3,4$ and 5

\section{Knockdown of Ae-CLIPB15 decreased proPO activation in Ae. aegypti}

The change in PO activity in the Ae-CLIPB15 and AeCLIPB22 knockdown adults was examined in the hemolymph at $24 \mathrm{~h}$ post-injection. Compared with the control group, the knockdown of $A e-C L I P B 15$ [dsGUS vs dsAeCLIPB15, $t$-test, $\left.t_{(12)}=3.765, P=0.0056\right]$ resulted in a significant decrease in $\mathrm{PO}$ activity. However, there was no significant difference in $\mathrm{PO}$ activity following the knockdown of $A e-C L I P B 22$ (dsGUS vs dsAe-CLIPB22, $t$-test, $t_{(12)}=0.7704, P=0.7839$ ] (Fig. 7). In general, the PO activity data showed that $A e-C L I P B 15$ is involved in the activation of proPO in Ae. aegypti, while Ae-CLIPB22 is not.

\section{Discussion}

Insects rely on their innate immune system to fight invading bacteria, fungi and parasites [16, 41-44]. The innate immune system plays an important role in limiting pathogen infection through phagocytosis, entrapment, secretion of physical barriers and melanization. These innate immune responses are mainly studied using insect models. CLIPs are essential components of the insect immune response. The CLIP catalytic domain is characterized

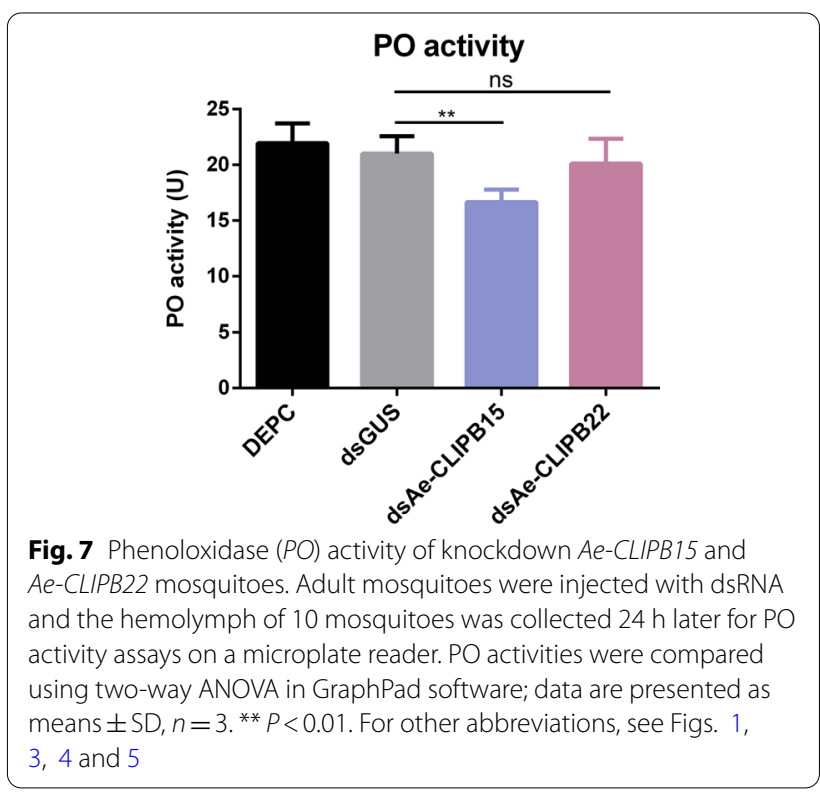

by a conserved Tryp_SPc domain with a catalytic ternary domain, which is composed of the amino acid residues His, Asp and Ser $[45,46]$. When the catalytic triad of SP mutates, the enzyme loses its catalytic activity and becomes a CSPH. The functions of CLIPs in innate immune responses include the proteolytic activation of the cytokine Spätzle to form active Toll ligands for the synthesis of AMPs and the specific activation of proPO required for melanization. In Ae. aegypti, the CLIP family is classified into five subfamilies-CLIPA, CLIPB, CLIPC, CLIPD, CLIPE-each of which comprises polygenes. In this study, we were able to confirm the roles of $\mathrm{Ae}$ CLIPB15 and Ae-CLIPB22, two members of the CLIPB subfamily of $A$ e. aegypti, in the innate immune response of adult Ae. aegypti mosquitoes.

The qPCR results showed that the kinetics of the induction of $A e-C L I P B 15$ and Ae-CLIPB22 differ following infection by Gram-negative and Gram-positive bacteria and fungi, but that these genes are not co-regulated. Interestingly, $A e-C L I P B 15$ and $A e-C L I P B 22$ are also induced by aseptic injury. Our results suggest that $A e-C L I P B 15$ and $A e-C L I P B 22$ may play a role in microbial defense and potentially a regulatory role in wound healing.

The immune response of arthropods is mainly regulated by two pathways, the Toll pathway and the IMD pathway [15]. In Ae. aegypti, NF-кB transcription factors REL1 and REL2 of the Toll pathway and IMD pathway are the main participants in the activation of genes coding for AMPs and other immune effector factors. Spz1C, Toll5A, CLIPB5 and CLIPB29 of Ae. aegypti have been shown to mediate the response of the Toll pathway 
to fungal infection [3, 47]. In An. gambiae, the IMD pathway is activated by peptidoglycan recognition protein or indirectly activated by a serine protease cascade [48]. However, according to current knowledge of insect immunity, CLIPs are not involved in the IMD pathway. Here, we used RNAi to knock down the dsRNA expression of $A e-C L I P B 15$ and $A e-C L I P B 22$ to study their role in the innate immunity of Ae. aegypti. After Ae-CLIPB15 and $A e-C L I P B 22$ were knocked down, the survival rate of Ae. aegypti was reduced after infection with pathogenic bacteria compared with that of wild type mosquitoes, and their resistance to bacterial infection decreased by $50 \%$.

The transcription of REL1 and REL2 was affected to varying degrees when $A e-C L I P B 15$ and $A e-C L I P B 22$ were knocked down. However, as the expression of REL1 and REL2 was mostly inhibited following Ae-CLIPB15 and $A e-C L I P B 22$ knockdown, we suggest that these latter genes are involved in the regulation of the Toll pathway and have an indirect effect on the activation of the IMD pathway. This may also explain why the survival rate of the adult mosquitoes that had been infected with bacteria and fungi after $A e-C L I P B 15$ and $A e-C L I P B 22$ knockdown was lower than that of the wild type mosquitoes. However, further biochemical study is definitely needed to examine whether $A e-C L I P B 15$ and $A e-C L I P B 22$ are involved in the regulation of the Toll pathway or the IMD pathway. In arthropods, the central component of the extracellular enzyme cascade is a CLIP which regulates various innate immune responses such as the Toll pathway and the IMD pathway [42]. Our results confirm that $A e-C L I P B 15$ and $A e-C L I P B 22$ participate in the regulation of innate immune responses in Ae. aegypti; however, their role in the regulation of a serine protease cascade remains to be clarified.

Mosquitoes that are capable of melanization initially received a great deal of attention as specific phenotypes that are resistant to parasites of public health importance, such as those that cause malaria and filariasis [49-51]. Melanization is a powerful defense response in Ae. aegypti. In this process, the $\mathrm{PO}$ activation system is triggered by soluble receptor molecules that recognize molecular patterns associated with pathogens or abnormal cells, resulting in the activation of serine proteases. These then activate a CLIPC, which in turn activates the terminal CLIPB protease in the cascade, also known as proPO activating protease (PAP) or proPO activating enzyme (PPAE). The activated PAP then cleaves the proPO to give PO. PO then acts as a catalyst for the formation of active intermediates of a quinone for the synthesis of melanin [52], which has a variety of protective functions. In addition, the formation of an active PO complex on the surface of the foreign body is mediated by one or more proteolytic inactivated CLIPAs, which need to be activated through proteolysis to play a role in the process. However, not all the CLIPs involved in the regulation of the proPO cascade activate proPO. Some CLIPs can inhibit melanization in An. gambiae [53]. Under normal physiological conditions, the proPO activation cascade is turned off, mainly by a single highly conserved serine protease inhibitor: Spn27A in Drosophila melanogaster [54, 55], Serpin-3 in Manduca sexta [56], and SRPN2 in mosquitoes [3, 17, 18, 57]. In this study, we knocked down Ae-CLIPB15 and $A e-C L I P B 22$ and explored their role in the proPO activation system. The knockdown of Ae-CLIPB15 led to a significant decrease in $\mathrm{PO}$ activity in the mosquitoes. However, there was no significant difference in PO activity in $A e-C L I P B 22$ knockdown mosquitoes. Ae$C L I P B 15$ was involved in the regulation of $\mathrm{PO}$ activity in Ae. aegypti, while $A e-C L I P B 22$ was not. This suggests that the CLIP family comprises serine proteases that are involved in a complex network of regulatory cascades that are independent of each other yet show some similarities. Further research is needed on this.

In summary, CLIPs are essential regulators of immune responses in many insects. All presently identified proteases that directly cleave insect proPO belong to the CLIPB subfamily. However, it is not clear how a single melanization cascade is regulated in the context of numerous physiological functions. Deciphering the regulatory mechanisms that lead to melanization in different defense responses, such as wound healing and pathogen isolation, is of particular interest. CLIPs may also have non-immune functions during insect development, e.g. embryonic dorsal pattern formation in Drosophila, and play a role in other physiological systems, all of which remain to be discovered [58]. To further improve our understanding of CLIP cascades and their role in a variety of immune responses, we also need to study other organisms, especially arthropod vectors, which show complex interactions between their immune systems and the pathogens that they transmit.

\section{Conclusions}

This study provides evidence for the role of Ae-CLIPB15 and $A e-C L I P B 22$ in the innate immune regulation of mosquitoes. Genetic interference of $A e-C L I P B 15$ and $A e-$ CLIPB22 could affect the resistance of adult Ae. aegypti to pathogens. However, further biochemical study is definitely needed to explore the regulatory mechanisms of innate immunity in Ae. aegypti. Our results suggest that $A e-C L I P B 15$ and Ae-CLIPB22 are potential targets for vector transmission control using RNAi technology. 


\section{Abbreviations}

AMP: Antimicrobial peptide; cDNA: Complementary DNA; CLIP: Clip domain serine protease; CSPH: Clip domain serine protease homolog; DEPC: Diethyl pyrocarbonate; dsRNA: Double-stranded RNA; GUS: $\beta$-Glucuronidase; IMD: Immunodeficiency; mRNA: messenger RNA; PAP: Prophenoloxidase activating enzyme; PO: Phenoloxidase; proPO: Prophenoloxidase; qPCR: Quantitative real-time polymerase chain reaction; RNAi: RNA interference; SPH: Serine protease homolog.

\section{Acknowledgements}

We are grateful to Prof. Tong-Yan Zhao of the Beijing Institute of Microbiology and Epidemiology for kindly providing the Ae. aegypti strain.

\section{Authors' contributions}

QH conceived and designed the study and critically revised the manuscript. $\mathrm{HCW}$ and $\mathrm{QHW}$ performed the experiments and analyzed the data; HCW also drafted the manuscript. BB commented on the experimental design and methodology and substantially revised the manuscript. YXL helped to analyze the data. All the authors read and approved the final manuscript.

\section{Funding}

This work was supported by the National Natural Science Foundation of China (31860702; 31960703)

\section{Availability of data and materials}

The data supporting the findings of this article are included in the article and its additional files.

\section{Declarations}

\section{Ethics approva}

Not applicable.

\section{Consent for publication}

Not applicable.

\section{Competing interests}

The authors declare that they have no competing interests.

\section{Author details}

${ }^{1}$ Laboratory of Tropical Veterinary Medicine and Vector Biology, School of Life Sciences, Hainan University, Haikou, Hainan 570228, People's Republic of China. ${ }^{2}$ One Health Institute, Hainan University, Haikou, Hainan 570228 , People's Republic of China.

Received: 16 August 2021 Accepted: 8 November 2021

Published online: 24 November 2021

\section{References}

1. Attardo GM, Hansen IA, Raikhel AS. Nutritional regulation of vitellogenesis in mosquitoes: implications for anautogeny. Insect Biochem Mol Biol. 2005;357:661-75

2. Rajah MM, Pardy RD, Condotta SA, Richer MJ, Sagan SM. Zika virus: emergence, phylogenetics, challenges, and opportunities. ACS Infect Dis. 2016:211:763-72.

3. Zou Z, Shin SW, Alvarez KS, Kokoza V, Raikhell AS. Distinct melanization pathways in the mosquito Aedes aegypti. Immunity. 2010;32:41-53.

4. Wang $\mathrm{YH}$, Chang MM, Wang XL, Zheng AH, Zou Z. The immune strategies of mosquito Aedes aegypti against microbial infection. Dev Comp Immunol. 2018:83:12-21.

5. Dimopoulos G. Insect immunity and its implication in mosquito-malaria interactions. Cell Microbiol. 2003:51:3-14.

6. Rodriguez-Andres J, Rani S, Varjak M, Chase-Topping ME, Beck MH, Ferguson MC, et al. Phenoloxidase activity acts as a mosquito innate immune response against infection with Semliki Forest virus. Plos Pathog. 2012:8(11):e1002977.
7. Hillyer JF, Schmidt SL, Christensen BM. Hemocyte-mediated phagocytosis and melanization in the mosquito Armigeres subalbatus following immune challenge by bacteria. Cell Tissue Res. 2003;313:117-27.

8. Yassine H, Kamareddine L, Chamat S, Christophides GK, Osta MA. A serine orotease homolog negatively regulates TEP1 consumption in systemic infections of the malaria vector Anopheles gambiae. J Innate Immun. 2014;66:806-18.

9. Yassine $H$, Kamareddine L, Osta MA. The mosquito melanization response is implicated in defense against the entomopathogenic fungus Beauveria bassiana. Plos Pathog. 2012;8(11):e1003029.

10. Brey PT, Lebrun RA, Papierok B, Ohayon H, Vennavalli S, Hafez J. Defense reactions by larvae of Aedes aegypti during infection by the aquatic fungus Lagenidium giganteum (Oomycete). Cell Tissue Res. 1988:2531:245-50.

11. Christensen BM. Observations on the immune response of Aedes trivittatus against Dirofilaria immitis. Trans R Soc Trop Med Hyg. 1981;75(3):439-43.

12. Michel K, Budd A, Pinto S, Gibson TJ, Kafatos FC. Anopheles gambiae SRPN2 facilitates midgut invasion by the malaria parasite Plasmodium berghei. EMBO Rep. 2005:69:891-7.

13. Habtewold T, Povelones M, Blagborough AM, Christophides GK. Transmission blocking immunity in the malaria non-vector mosquito Anopheles quadriannulatus species A. Plos Pathog. 2008;45:e1000070-e.

14. Zhang X, An C, Sprigg K, Michel K. CLIPB8 is part of the prophenoloxidase activation system in Anopheles gambiae mosquitoes. Insect Biochem Mol Biol. 2016;71:106-15.

15. Xi Z, Ramirez JL, Dimopoulos G. The Aedes aegypti Toll pathway controls dengue virus infection. Plos Pathog. 2008;47:e1000098.

16. Hoffmann JA, Reichhart J-M. Drosophila innate immunity: an evolutionary perspective. Nat Immunol. 2002;32:121-6.

17. Waterhouse RM, Kriventseva EV, Meister S, Xi Z, Alvarez KS, Bartholomay LC, et al. Evolutionary dynamics of immune-related genes and pathways in disease-vector mosquitoes. Science (New York, NY). 2007;3165832:1738-43.

18. Christophides GK, Zdobnov E, Barillas-Mury C, Birney E, Blandin S, Blass C, et al. Immunity-related genes and gene families in Anopheles gambiae. Science (New York, NY). 2002;2985591:159-65.

19. Ross J, Jiang H, Kanost MR, Wang Y. Serine proteases and their homologs in the Drosophila melanogaster genome: an initial analysis of sequence conservation and phylogenetic relationships. Gene. 2003;304:117-31.

20. Zou Z, Evans JD, Lu Z, Zhao P, Williams M, Sumathipala N, et al. Comparative genomic analysis of the Tribolium immune system. Genome Biol. 2007;88:R177.

21. Zou Z, Lopez DL, Kanost MR, Evans JD, Jiang H. Comparative analysis of serine protease-related genes in the honey bee genome: possible involvement in embryonic development and innate immunity. Insect Mol Biol. 2006;155:603-14.

22. Cao X, He Y, Hu Y, Zhang X, Wang Y, Zou Z, et al. Sequence conservation, phylogenetic relationships, and expression profiles of nondigestive serine proteases and serine protease homologs in Manduca sexta. Insect Biochem Mol Biol. 2015;62:51-63.

23. Gulley MM, Zhang $X$, Michel $K$. The roles of serpins in mosquito immunology and physiology. J Insect Physiol. 2013;592:138-47.

24. Gubb D, Sanz-Parra A, Barcena L, Troxler L, Fullaondo A. Protease inhibitors and proteolytic signalling cascades in insects. Biochimie. 2010;9212:1749-59.

25. Park JW, Kim CH, Rui J, Park KH, Ryu KH, Chai JH, et al. Beetle immunity. Adv Exp Med Biol. 2010;708:163-80.

26. Jiang $H$, Vilcinskas A, Kanost MR. Immunity in lepidopteran insects. Adv Exp Med Biol. 2010;708:181-204.

27. Kwon TH, Kim MS, Choi HW, Joo CH, Cho MY, Lee BL. A masquerade-like serine proteinase homologue is necessary for phenoloxidase activity in the coleopteran insect Holotrichia diomphalia larvae. Eur J Biochem. 2000:26720:6188-96.

28. Lee KY, Zhang R, Kim MS, Park JW, Park HY, Kawabata S-I, et al. A zymogen form of masquerade-like serine proteinase homologue is cleaved during pro-phenoloxidase activation by $\mathrm{Ca} 2+$ in coleopteran and Tenebrio molitor larvae. Eur J Biochem. 2002;26917:4375-83.

29. Yu X-Q, Jiang H, Wang Y, Kanost MR. Nonproteolytic serine proteinase homologs are involved in prophenoloxidase activation in the tobacco hornworm, Manduca sexta. Insect Biochem Mol Biol. 2003:332:197-208. 
30. Gupta S, Wang Y, Jiang H. Manduca sexta prophenoloxidase (proPO) activation requires proPO-activating proteinase (PAP) and serine proteinase homologs (SPHs) simultaneously. Insect Biochem Mol Biol. 2005;353:241-8.

31. Wang $Y, L u Z Q$, Jiang HB. Manduca sexta proprophenoloxidase activating proteinase-3 (PAP3) stimulates melanization by activating proPAP3, proSPHs, and proPOs. Insect Biochem Mol Biol. 2014;50:82-91.

32. Lu Z, Jiang H. Expression of Manduca sexta serine proteinase homolog precursors in insect cells and their proteolytic activation. Insect Biochem Mol Biol. 2008;38(1):89-98.

33. Wang $Y$, Jiang $H$. A positive feedback mechanism in the Manduca sexta prophenoloxidase activation system. Insect Biochem Mol Biol. 2008;388:763-9.

34. Kim MS, Baek MJ, Lee MH, Park JW, Lee SY, Soderhall K, et al. A new easter-type serine protease cleaves a masquerade-like protein during prophenoloxidase activation in Holotrichia diomphalia larvae. J Biol Chem. 2002;27742:39999-40004.

35. Wang R, Lee SY, Cerenius L, Soderhall K. Properties of the prophenoloxidase activating enzyme of the freshwater crayfish Pacifastacus leniusculus. Eur J Biochem. 2001;2684:895-902.

36. Hillyer JF, Schmidt SL, Fuchs JF, Boyle JP, Christensen BM. Age-associated mortality in immune-challenged mosquitoes (Aedes aegypti) correlates with a decrease in haemocyte numbers. Cell Microbiol. 2005;71:39-51.

37. Guan H, Wang M, Liao C, Liang J, Mehere P, Tian M, et al. Identification of aaNAT5b as a spermine $\mathrm{N}$-acetyltransferase in the mosquito, Aedes aegypti. PLOS ONE. 2018;13(3):e0194499.

38. Ballester M, Cordon R, Folch JM. DAG expression: high-throughput gene expression analysis of real-time PCR data using standard curves for relative quantification. PLoS ONE. 2013;8(11):e80385.

39. Whyard S, Erdelyan CNG, Partridge AL, Singh AD, Beebe NW, Capina R. Silencing the buzz: a new approach to population suppression of mosquitoes by feeding larvae double-stranded RNAs. Parasite Vector. 2015;8:96.

40. Jiang H, Wang Y, Yu X-Q, Kanost MR. Prophenoloxidase-activating proteinase-2 from hemolymph of Manduca sexta. A bacteria-inducible serine proteinase containing two clip domains. J Biol Chem. 2003;2786:3552-61.

41. Cirimotich CM, Dong YM, Garver LS, Sim SZ, Dimopoulos G. Mosquito immune defenses against Plasmodium infection. Dev Comp Immunol. 2010;344:387-95.

42. Lemaitre B, Hoffmann J. The host defense of Drosophila melanogaster. Annu Rev Immunol. 2007;25:697-743.

43. Xing LS, Yuan CF, Wang ML, Lin Z, Shen BC, Hu ZH, et al. Dynamics of the interaction between cotton bollworm Helicoverpa armigera and nucleopolyhedrovirus as revealed by integrated transcriptomic and proteomic analyses. Mol Cell Proteomics. 2017;166:1009-28.

44. Xiong G-H, Xing L-S, Lin Z, Saha TT, Wang C, Jiang H, et al. High throughput profiling of the cotton bollworm Helicoverpa armigera immunotranscriptome during fungal and bacterial infections. BMC Genomics. 2015. https://doi.org/10.1186/s12864-015-1509-1.

45. Di Cera E. Serine proteases. IUBMB Life. 2009;615:510-5.

46. Perona JJ, Craik CS. Structural basis of substrate specificity in the serine proteases. Protein Sci. 1995;43:337-60.

47. Shin SW, Kokoza V, Bian G, Cheon H-M, Kim YJ, Raikhel AS. REL1, a homologue of Drosophila dorsal, regulates Toll antifungal immune pathway in the female mosquito Aedes aegypti. J Biol Chem. 2005;28016:16499-507.

48. Blumberg BJ, Trop S, Das S, Dimopoulos G. Bacteria- and IMD pathwayindependent immune defenses against Plasmodium falciparum in Anopheles gambiae. PLoS ONE. 2013;8-9:e72130.

49. Collins FH, Sakai RK, Vernick KD, Paskewitz S, Seeley DC, Miller LH, et al. Genetic selection of a Plasmodium-refractory strain of the malaria vector Anopheles gambiae. Science (New York, NY). 1986;2344776:607-10.

50. Chen CC, Laurence BR. Selection of a strain of Anopheles quadrimaculatus with high filaria encapsulation rate. J Parasitol. 1987;732:418-9.

51. Hurd H, Taylor PJ, Adams D, Underhill A, Eggleston P. Evaluating the costs of mosquito resistance to malaria parasites. Evol Int J Organ Evol. 2005;59(12):2560-72.

52. Cerenius $L$, Soderhall K. The prophenoloxidase-activating system in invertebrates. Immunol Rev. 2004;198:116-26.

53. Barillas-Mury C. CLIP proteases and Plasmodium melanization in Anopheles gambiae. Trends Parasitol. 2007;237:297-9.

54. Ligoxygakis P, Pelte N, Ji C, Leclerc V, Duvic B, Belvin M, et al. A serpin mutant links Toll activation to melanization in the host defence of Drosophila. EMBO J. 2002;21(23):6330-7.

55. De Gregorio E, Han S-J, Lee W-J, Baek M-J, Osaki T, Kawabata S-I, et al. An immune-responsive serpin regulates the melanization cascade in Drosophila. Dev Cell. 2002;3(4):581-92.

56. Zhu Y, Wang Y, Gorman MJ, Jiang H, Kanost MR. Manduca sexta serpin-3 regulates prophenoloxidase activation in response to infection by inhibiting prophenoloxidase-activating proteinases. J Biol Chem. 2003;278(47):46556-64.

57. Bartholomay LC, Waterhouse RM, Mayhew GF, Campbell CL, Michel $\mathrm{K}$, Zou Z, et al. Pathogenomics of Culex quinquefasciatus and metaanalysis of infection responses to diverse pathogens. Science. 2010;3306000:88-90.

58. Castillejo-Lopez C, Hacker U. The serine protease Sp7 is expressed in blood cells and regulates the melanization reaction in Drosophila. Biochem Biophys Res Commun. 2005;3382:1075-82.

\section{Publisher's Note}

Springer Nature remains neutral with regard to jurisdictional claims in published maps and institutional affiliations.
Ready to submit your research? Choose BMC and benefit from:

- fast, convenient online submission

- thorough peer review by experienced researchers in your field

- rapid publication on acceptance

- support for research data, including large and complex data types

- gold Open Access which fosters wider collaboration and increased citations

- maximum visibility for your research: over $100 \mathrm{M}$ website views per year

At BMC, research is always in progress.

Learn more biomedcentral.com/submissions 